\title{
REVIEW
}

\section{Use of tissue adhesives in the management of paediatric lacerations}

\section{A Mattick}

Emerg Med J 2002;19:382-385

The ideal method of wound closure in children who present to the accident and emergency department with lacerations, is painless, rapid, easy to perform, safe, and results in minimal scarring. Tissue adhesives have relatively recently been used as a "no needle" alternative to conventional suturing. This review reports on the development of tissue adhesives and analyses how close they are to this ideal method of wound closure.

A Mattick, Department of Accident and Emergency Department, The Royal Infirmary of Edinburgh, Lauriston Place, Edinburgh EH3 9YW, UK

Correspondence to: Mr A Mattick; anthony.mattick@virgin.net acerations requiring formal wound closure account for a significant number of all -childhood injuries presenting to the accident and emergency department. Figures vary from $30 \%-40 \%$ of all paediatric injuries and $3 \%-4.4 \%$ of all paediatric attendances. ${ }^{1-4}$ Their management represents a unique challenge because of the developmental and behavioural characteristics of this group of patients. Indeed, to a child, the thought of needles, sutures, or staples may be worse than the actual injury itself. Therefore, the ideal method of wound closure in children should be not only painless but also rapid, easy to perform, safe, with few complications, and result in minimal scarring. ${ }^{56}$ Clearly, closure with conventional suturing techniques fail to accomplish all these goals in their entirety. The recent advances made in the field of tissue adhesives have led to its development as a "no needle" method of wound closure that may allay the fears of the frightened child during laceration repair, and provide a good cosmetic result without the need for sedation or anaesthetics.

\section{OBJECTIVE}

This review reports on the development of these tissue adhesives and analyses how close to the ideal method this technique is in repairing children's lacerations.

\section{METHODOLOGY}

A literature search was undertaken using the Medline 1966-2001 and Cochrane databases. The key words used were: tissue adhesives, cyanoacrylates, Dermabond, Histacryl Blue, glue, wounds and injuries, laceration, child, and paediatric. Cross referencing was then undertaken manually.

\section{DEVELOPMENT OF CYANOACRYLATE TISSUE ADHESIVES}

Cyanoacrylate adhesives were first synthesised in 1949 by Ardis ${ }^{7}$ but the potential for clinical use was not reported until 1959. ${ }^{8}$ As a group they have a common chemical structure but subtle variations in the alkyl group can change the properties of each individual tissue adhesive ${ }^{9}$ (fig 1). Cyanoacrylates are liquid monomers that can polymerise to form a rapid and strong adhesive. ${ }^{10}$ This process occurs when they come into contact with anions, such as those found in skin moisture or wound exudate. Thus, when applied to the edges of a wound a strong bond will develop, allowing wound closure. ${ }^{911}$

The early derivatives methyl-2-cyanoacrylate (Eastman 910 Monomer) and ethyl-2 cyanoacrylate (Krazy glue) produced good bonding but resulted in histotoxicity giving rise to wound inflammation. ${ }^{12}$ Their clinical use was therefore hindered.

The causes of this histotoxicity were short chain alkyl derivatives, which degraded rapidly into cyanoacetate and formaldehyde. These breakdown products could not be excreted at a sufficient rate to prevent their accumulation locally in the tissues, leading to levels that resulted in inflammation. It was not until the development of longer chain alkyl derivatives, which degraded more slowly, that tissue adhesives became useful clinically. ${ }^{13}$ Their slow degradation enabled excretion of the toxic breakdown products preventing a build up. These newer derivatives are N-butyl-2-cyanoacrylate (Histoacryl Blue), the first tissue adhesive to be successfully used clinically, and the most recent formulation, octyl-2-cyanoacrylate (Dermabond), which has reputed advantages over the Histoacryl Blue. ${ }^{613} 14$ The following review thus concentrates on these two tissue adhesives.

\section{APPLICATION OF ADHESIVES FOR WOUND CLOSURE}

After routine wound management the edges of the wounds are held together with either forceps or the operator's fingers before the adhesive is applied. Histoacryl Blue is applied as beads intermittently along the edge of the laceration whereas Dermabond is painted on in layers. ${ }^{11}{ }^{15}$ Whichever adhesive is used, the edges of the wound are held together for up to a minute to enable sufficient polymerisation and bond formation to achieve closure. Maximum strength is

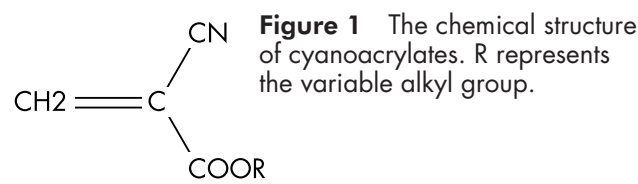


usually achieved within two minutes. It is important that the adhesives are placed topically onto the wound edges and not allowed to enter the wound itself, as this will impair healing. A sterile, waterproof seal is formed, allowing the patient to briefly shower but not to soak. No additional dressing need be applied, unless it is thought that the child may pick at the wound, and the adhesive is allowed to slough off naturally in one to two weeks. ${ }^{69}{ }^{14}$ Proficiency in the technique of adhesive application has been shown to been rapidly attained in those with wound management experience. ${ }^{11}$ Specific hazards include gluing oneself to the child and getting glue in the child's eye. The former embarrassing situation is remedied by applying petroleum jelly or acetone to loosen the bond and then peel, not pull the surfaces apart. The second hazard is usually avoided by protection of the child's eyes with gauze when closing facial wounds. If this fails and adhesive inadvertently enters the eye then ophthalmic ointment should be applied, and the eye patched. The glue will slough off in one to two days.

\section{CLINICAL TRIALS INVOLVING THE TISSUE ADHESIVES}

\section{N-butyl-2-cyanoacrylate (Histoacryl Blue)}

Since 1988 numerous uncontrolled reports in the literature have advocated the use of Histoacryl Blue in the repair of paediatric lacerations. They highlight the virtues of its ease of use, patient acceptability, low complication rates, and excellent cosmetic outcome. The number of children involved in these observational studies varies from 50-2600. ${ }^{16-19}$ Similar studies have reported the same outcomes in repairing adult lacerations ${ }^{20}$ and in the closure of elective surgical incisions. ${ }^{21-23}$ All of these studies are, however, limited in that they lack control groups and blinded, validated outcome measures. It was not until 1993 that the first of three randomised controlled trials compared Histoacryl Blue with suturing in the closure of paediatric lacerations. Quinn et al randomised 81 children with facial lacerations less than $4 \mathrm{~cm}$ in length for repair using either Histoacryl Blue or 5/0 non-absorbable sutures. ${ }^{24}$ Three month post-repair photographs were shown to two plastic surgeons blinded as to the method of closure. They independently rated the scars using two validated cosmesis scales. ${ }^{25}$ The first is a visual analogue scale on which the surgeon marks a $100 \mathrm{~mm}$ line, annotated with "worse scar" and "best scar" at either ends, where he feels the scar best fits. The second is a categorical scale where the surgeon is provided with criteria to rate the scar into three categories; unacceptable, adequate, or excellent. Using these scoring systems the study showed no difference in the cosmetic outcome in the two groups. The study also demonstrated that the tissue adhesive technique was a faster procedure and perceived to be less painful. Both groups had low rates of complications.

In the second of these types of trials Bruns et al showed similar findings after randomising 61 children with "lowtension" facial and scalp lacerations. ${ }^{26}$ The cosmetic appearance in both groups was judged comparable at two months and remained so at one year. ${ }^{27}$ The authors also commented that parents whose offspring had been treated with tissue adhesives were more likely to recommend this over suturing to other parents.

In the third trial Barnett et al confirmed the findings of the previous two studies. ${ }^{4}$ In this, the largest of the three trials, 163 children were randomised for closure with tissue adhesive or sutures. For the first time wounds other than those on the face or scalp were included.

When focusing on these three studies it must be emphasised that the great majority of lacerations were low tension in nature and involved the face or scalp. All were less than $5 \mathrm{~cm}$ in length with the highest mean length of the three studies, $1.6 \mathrm{~cm}$. In clinical practice, however, this is a realistic pattern. ${ }^{28}$
Therefore, there is now clinical evidence that this tissue adhesive has advantages over sutures. It is a faster wound closure technique and seems to be less painful as judged by children and their parents. This is achieved with a comparable cosmetic outcome and an equally low complication rate.

\section{Octyl-2-cyanoacrylate (Dermabond)}

The most recent cyanoacrylate product is an octyl based derivative and is the first to gain FDA approval. ${ }^{15}$ This longer chain formulated product is a combination of monomers and a plasticiser that results in an adhesive with a three dimensional breaking strength four times that of butyl derivatives, (Histoacryl Blue). ${ }^{29}$ The increased strength combined with the greater degree of flexibility from the plasticisers has led to the possibility of enhanced performance over the butyl derivatives. To prove this it would have to close longer wounds, in areas other than just low tension, while maintaining excellent scarring with a low complication rate.

The first randomised controlled trial comparing Dermabond to sutures was by Quinn et al in 1997. They enrolled 136 adults with low tension lacerations of the face, torso, and extremities. The results showed Dermabond to be faster, less painful, and with similar cosmetic outcome to sutures. ${ }^{30} 31$ Singer et al showed comparable findings in a similar trial, which included both adults and children. ${ }^{32}$ The average length of the lacerations in both of these trials was only just over $2 \mathrm{~cm}$ and if the surgeon subjectively felt that subcuticular sutures were justified to reduce wound tension, then these were used. Thus, it may be argued that the improved physical properties of this new tissue adhesive had not been tested in these studies

They were, however, tested to some degree by Mar et al when Dermabond was compared with subcuticular sutures in the closure of 50 wounds. The wounds averaged $8 \mathrm{~cm}$ in length and comparable scarring was achieved. ${ }^{33}$ These wounds were all clean, incised wounds that had received additional subcutaneous suturing to augment wound strength.

To date, only two studies compare Dermabond with sutures in a purely paediatric population. The first involved 83 children whose lacerations were mainly facial (that is, low tension) with an average length less than $1.2 \mathrm{~cm}$. Some of the wounds had subcutaneous suturing and the two methods of closure showed comparable cosmetic results. ${ }^{34}$ In the second study, Sexena and Willital reported on 64 children with extremity lacerations in high tension areas, for example, knee, elbow, etc. ${ }^{35}$ The mean length of wound was $2.4 \mathrm{~cm}$. This seems to be the only study to actively seek out and test a tissue adhesive in high tension areas. They confirmed that there was no difference in scar formation or complications such as wound dehiscence between the Dermabond and suture groups. The wounds were, however, all splinted for one week to minimise tension at the wound edges. Therefore, once again, the enhanced physical properties of this new tissue adhesive seem to have been only partially tested.

Throughout these studies Dermabond seems to show all the advantages of Histoacryl Blue when compared with conventional suturing. Therefore it is quick, well tolerated, with low rates of complications, and a comparable cosmetic outcome.

\section{Comparison of Dermabond with Histoacryl Blue}

Dermabond has superior physical qualities to Histoacryl Blue. The two tissue adhesives, however, have only been compared with one another in one clinical trial. Osmond et al compared the two products on the facial lacerations of 94 children. ${ }^{36}$ All lacerations were less than $4 \mathrm{~cm}$ long (mean of $1.3 \mathrm{~cm}$ ). No difference was found between the groups when comparing cosmetic outcome, time to perform the procedure, ease of use of the products, child discomfort, or complications.

\section{Comparison of Dermabond with Steristrips}

Adhesive strips such as Steristrips represent the other "no needle" alternative to sutures. They are an acceptable method 
Table 1 Factors dictating advantage or disadvantage of tissue adhesive over sutures, in management of children's lacerations

\begin{tabular}{ll}
\hline Advantages & Disadvantages \\
\hline Virtually painless & Poor result if applied into wound \\
No needlestick risk if used as directed & Heat discomfort may occur on application \\
Low cost & Must avoid contact with eyes \\
Dressing sloughs off; no need for removal & Not proven on areas of tension \\
Acts as a waterproof dressing & Not for use on mucous membranes \\
No conscious sedation or anaesthetic required if only simple wound toilet & May lead to inadequate wound toilet as sedation or anaesthetic often not used \\
Rapid & May bond, literally, with child \\
\hline
\end{tabular}

of closure of lacerations that are small and under low tension. $^{5}$ The main disadvantages are that they come away from the skin if they become wet, and that they cannot reliably be used over joints. They also cannot be applied to hairy skin.

In a unique randomised controlled trial, Steristrips were compared with Dermabond in the closure of 44 children's lacerations. ${ }^{37}$ The wounds were all short, of low tension, and involved non-hairy skin. No difference was found in cosmetic outcome or complication rates.

\section{FURTHER FACTORS INVOLVING TISSUE ADHESIVES Advantages Financial}

In a cost comparison of Histoacryl Blue and non-absorbable sutures in the closure of facial lacerations, the tissue adhesive was the most cost efficient. ${ }^{38}$ The calculated saving per child at that time was \$C49.60. This was mainly attributable to the follow up costs entailed in suture removal. These figures are based on the treatment of 10 children from each vial of tissue adhesive (despite the fact that it is licensed for single use only). This was achieved by attaching a sterile 25 gauge needle to the hub of the applicator for each application, an approach that has been advocated by many other authors. ${ }^{4222426}$ Even so, a saving would still have been achieved even if only one application was obtained from each vial.

\section{Antimicrobial}

In animal studies, contaminated wounds closed with Histoacryl Blue were found to have bacterial growth rates significantly less than those closed with sutures. ${ }^{39}{ }^{40}$ Laboratory tests confirm both tissue adhesives to have antimicrobial effects. ${ }^{41}$

Langer's lines

In one study closure with sutures resulted in a cosmetically worse scar in lacerations that deviated by more than $20^{\circ}$ from Langer's lines. In contrast, closure with the tissue adhesive was unaffected by the wound's orientation with Langer's lines. ${ }^{42}$

\section{Miscellaneous}

As no suture removal is required with this technique formal follow up is unnecessary. This assumes the parent or guardian is told to return at signs of infection or wound dehiscence. Finally, when used as licensed, no needles are involved and there is no risk of needlestick injury. ${ }^{6}{ }^{15}{ }^{43}$ The latter does not apply if multiple use from the one vial of Histoacryl Blue is adopted.

\section{Disadvantages}

\section{Wound strength}

In one animal study the wound strength after immediate closure of a laceration with Histoacryl Blue was 10\%-15\% that of a similar wound closed with suturing..$^{40}$ A further study confirmed this relative weakness at day $4^{44}$ but by day 7 it has been shown that this difference disappears. ${ }^{40}$ One further technical problem is that after polymerising the tissue adhesive becomes brittle and may be subject to fracturing if used on skin creases, long lacerations, or areas of movement. ${ }^{30}$ The three major randomised controlled trials using Histoacryl Blue, however, showed no significant difference in wound dehiscence between the methods of closure. ${ }^{4426}$ Therefore, the clinical relevance of this relative early weakness and inflexibility would seem uncertain until it is noted that these major trials were all in short, low tension wounds.

\section{Wound reactions}

When applied correctly histotoxicity is negligible. However, incorrect placement of the tissue adhesive into the wound itself results in some minor histotoxicity, impaired healing, and can result in an unacceptable scar. ${ }^{12}$ The adhesive can act as a barrier to epithelisation and result in a wider scar. ${ }^{9}$ Furthermore, during polymerisation the reaction produces a small amount of heat that occasionally produces discomfort. ${ }^{19}$

\section{Potential carcinogenicity}

Data from one study reported that isobutyl-2-cyanoacrylate implanted into rat peritoneum induced sarcomas. ${ }^{45}$ In this trial, however, the rats had a predisposition for sarcoma, the study was uncontrolled, and the amounts used were 100 times greater than those used in humans. Further studies have failed to show any evidence of carcinogenicity. ${ }^{46}$ Despite this, it is thought to have been the stumbling block for failure to achieve FDA approval in the USA and so preventing its use there.

\section{Conclusion}

The cyanoacrylate tissue adhesives Histoacryl Blue and Dermabond are excellent "no needle" alternatives for the closure of selected paediatric lacerations (table 1). The method is faster and less painful than suturing, while producing an equivalent cosmetic outcome with an equally low complication rate. Suitable wound types are those that are short, clean, and under low tension. Dermabond has the physical properties to potentially improve on the size and type of laceration that can be closed, but clinical trials to date do not appear to test this claim fully.

Despite the encouraging advantages of the tissue adhesives it is important to remember that wound closure is only part of the wound management in these children. Many wounds require irrigation, debridement, and deep sutures, which may require time, conscious sedation or anaesthesia. ${ }^{47}$ Although tissue adhesives are rapid and relatively painless, their use in inappropriate situations will lead to poor technical and cosmetic results.

\section{ACKNOWLEDGEMENT}

I thank Dr C Robertson and Dr T Beattie for their comments and suggestions in the preparation of this review.

Funding: none.

Conflicts of interest: none. 


\section{REFERENCES}

1 Silbert J, Maddocks G, Brown B. Childhood accidents-an endemic of epidemic proportions. Arch Dis Child 1981;56:225-34.

2 Baker MD, Lanuti M. The management and outcome of lacerations in urban children. Ann Emerg Med 1990;19:1001-5.

3 Rivera FP, Bergman AB, LoGerfo JF, et al. Epidemiology of childhood injuries II. Sex differences in injury rates. Am J Dis Child

1982;136:502-6.

4 Liebelt EL. Current concepts in laceration repair. Curr opin Pediatr 1997;9:459-64

5 Osmond MH. Pediatric wound management: the role of tissue adhesives. Pediatr Emerg Care 1999;15:137-40.

6 Ardis AE. US Patent No 2467926 and 2467927 (1949).

7 Coover HN, Joyner FB, Sheere $\mathrm{NH}$, et al. Chemistry and performance of cyanoacrylate adhesive. J Soc Plast Surg Engl 1959;15:5-6.

8 Maw J, Quinn J. Cyanoacrylate Tissue Adhesives. Am J Cosmetic Surg $1997 ; 14: 413-16$.

9 Coover HN, Joyner FB, Sheere $\mathrm{NH}$, et al. Chemistry and performance of cyanoacrylate adhesive. SPE Journal 1959;413-17.

10 Hollander JE, Singer AJ. Application of tissue adhesives: rapid attainment of proficiency. Stony Brook Octylcyanoacrylate Study Group. Acad Emerg Med 1998:5:1012-17.

11 Toriumi DM. Raslan WF. Friedman M, et al. Histotoxicity of cyanoacrylate tissue adhesives. A comparative study. Arch Otolaryngol Head Neck Surg 1990;116:546-50

12 Trott AT. Cyanoacrylate tissue adhesives. An advance in wound care. JAMA 1997;277:1559-60.

13 Penoff J. Skin closures using cyanoacrylate tissue adhesives. Plastic Surgery Educational Foundation DATA Committee. Device and Technique Assessment. Plast Reconstr Surg 1999;103:730-1.

14 Hollander JE. Singer AJ. Laceration management. Ann Emerg Med 1999;34:356-67.

15 Watson DP. Use of cyanoacrylate tissue adhesive for closing facial lacerations in children. BM 1989;299:1014.

16 Mizrahi S, Bickel A Ben-Layish E. Use of tissue adhesives in the repair of lacerations in children. J Pediatr Surg 1988;23:312-13.

17 Messi G, Marchi AG. Evaluation of skin laceration repair by tissue adhesives in the pediatric emergency room. Panminerva Med 1992;34:77-80.

18 Elmasalme FN, Matbouli SA, Zuberi MS. Use of tissue adhesive in the closure of small incisions and lacerations. J Pediatr Surg 1995; 30:837-8

19 Applebaum JS, Zalut T, Applebaum D. The use of tissue adhesion for traumatic laceration repair in the emergency department. Ann Emerg Med. 1993;22:1190-2

20 Dalvi A, Faria M, Pinto A. Non-suture closure of wound using cyanoacrylate. J Postgrad Med 1986;32:97-100.

21 Ellis DA, Shaikh A. The ideal tissue adhesive in facial plastic and reconstructive surgery. J Otolarygol 1990;19:68-72

22 Amiel GE, Sukhotnik I, Kawar B, et al. Use of N-butyl-2-cyanoacrylate in elective surgical incisions-longterm outcomes. J Am Coll Surg 1999;189 :21-5.

23 Quinn JV, Drzewiecki A, Li MM, et al. A randomized, controlled trial comparing a tissue adhesive with suturing in the repair of pediatric facial lacerations. Ann Emerg Med 1993;22:1130-5.

24 Quinn JV, Drzewiecki AE, Stiell IG, et al. Appearance scales to measure cosmetic outcomes of healed lacerations. Am J Emerg Med1995;13:229-31.

25 Bruns TB, Simon HK, McLario DJ, et al. Laceration repair using a tissue adhesive in a children's emergency department. Pediatrics 1996;98:673-5.
26 Simon HK, McLario DJ, Bruns TB, et al. Long-term appearance of lacerations repaired using a tissue adhesive. Pediatrics 1997;99:193-5.

27 Barnett P, Jarmen FC, Goodge J, et al. Randomized trial of histoacryl blue tissue adhesive glue versus suturing in the repair of paediatric lacerations. J Paediatr Child Health 1998;34:548-50.

28 Hollander JE, Singer AJ, Valentine S. Comparison of wound care practices in pediatric and adult lacerations repaired in the emergency department. Pediatr Emerg Care 1998;14:15-18.

29 Osmond MH, Klassen TP, Quinn JV. Economic comparison of a tissue adhesive and suturing in the repair of pediatric facial lacerations. $J$ Pediatr 1995; 126:892-5.

30 Howell JM, Bresnahan KA, Stair TO, et al. Comparison of effects of suture and cyanoacrylate tissue adhesive on bacterial counts in contaminated lacerations. Antimicrob Agents Chemother 1995;39:559-60.

31 Noordzii JP, Foresman PA, Rodeheaver GT, et al. Tissue adhesive wound repair revisited. J Emerg Med 1994;12:654-9.

32 Simon HK, Zempsky WT, Bruns TB, et al. Lacerations against Langer's lines: to glue or suture? J Emerg Med 1998;16:185-9.

33 Singer AJ, Hollander JE, Quinn JV. Evaluation and management of traumatic lacerations. N Engl J Med 1997;337:1 142-8.

34 Bresnahan KA, Howell JM, Wizorek J. Comparison of tensile strength of cyanoacrylate tissue adhesive closure of lacerations versus suture closure. Ann Emerg Med 1995;26:575-8.

35 Quinn J, Wells G, Sutcliffe T, Jarmuske $M$, et al. A randomized trial comparing octylcyanoacrylate tissue adhesive and sutures in the management of lacerations. JAMA 1997;277:1527-30.

36 Reiter A. Induction of sarcomas by the tissue-binding substance Histoacryl-glue in the rat. Z Exp Chir Transplant Kunstliche Organe 1987;20:50-60.

37 King H. Evaluation of the undesirable side-effects of the surgical use of Histoacryl glve with special regard to possible carcinogenicity. Basle, Switzerland: RCC Institute for contract research in toxicology and ecology, Project 064315, March 1986

38 Perry LC. An evaluation of acute incisional strength with traumaseal surgical tissue adhesive wound closure. Leonia, NJ: Dimensional Analysis Systems, 1995

39 Quinn J. Wells G. Sutcliffe T, et al. Tissue adhesive versus suture wound repair at 1 year: randomized clinical trial correlating early, 3-month, and 1-year cosmetic outcome. Ann Emerg Med 1998;32:645-9.

40 Singer AJ, Hollander JE, Valentine SM, et al. Prospective, randomized, controlled trial of tissue adhesive (2-octylcyanoacrylate) vs standard wound closure techniques for laceration repair. Stony Brook

Octylcyanoacrylate Study Group. Acad Emerg Med 1998;5:94-9.

41 Maw JL, Quinn JV, Wells GA, et al. A prospective comparison of Octylcyanoacrylate tissue adhesive and suture for the closure of head and neck incisions. J Otolaryngol 1997;26:26-30.

42 Bruns TB, Robinson BS, Smith R, et al. A new tissue adhesive for laceration repair in children. J Pediatr 1998;132:1067-70.

43 Saxena AK, Willital GH. Octylcyanoacrylate tissue adhesive in the repair of pediatric extremity lacerations. Am Surg 1999;65:470-2.

44 Quinn JV, Rotomar K, Osmond MH. Antimicrobial effects of a new tissue adhesive. Acad Emerg Med 1996;3:536-7.

45 Osmond MH, Quinn JV, Sutcliffe T, et al. A randomized, clinical trial comparing butylcyanoacrylate with octylcyanoacrylate in the management of selected pediatric facial lacerations. Acad Emerg Med 1999;6:171-7.

46 Mattick A, Clegg G, Beattie TB, et al. A comparison of Steristrips versus glue for the closure of lacerations in a pediatric accident and emergency department. Ann Emerg Med 2000;35:S24

47 Singer AJ, Hollander JE.Tissue adhesives for laceration closure. [Letter]. JAMA 1997;278:703-4. 